\title{
Time-dependent upregulation of electron transport with concomitant induction of regulated excitation dissipation in Haslea diatoms
}

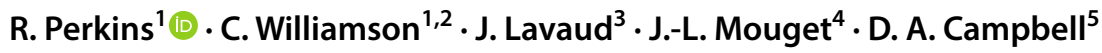

Received: 18 August 2017 / Accepted: 11 April 2018 / Published online: 16 April 2018

(c) The Author(s) 2018

\begin{abstract}
Photoacclimation by strains of Haslea "blue" diatom species H. ostrearia and H. silbo sp. nov. ined. was investigated with rapid light curves and induction-recovery curves using fast repetition rate fluorescence. Cultures were grown to exponential phase under $50 \mu \mathrm{mol} \mathrm{m} \mathrm{m}^{-2} \mathrm{~s}^{-1}$ photosynthetic available radiation (PAR) and then exposed to non-sequential rapid light curves where, once electron transport rate (ETR) had reached saturation, light intensity was decreased and then further increased prior to returning to near growth light intensity. The non-sequential rapid light curve revealed that ETR was not proportional to the instantaneously applied light intensity, due to rapid photoacclimation. Changes in the effective absorption cross sections for open PSII reaction centres $\left(\sigma_{\mathrm{PSII}}{ }^{\prime}\right)$ or reaction centre connectivity $(\rho)$ did not account for the observed increases in ETR under extended high light. $\sigma_{\text {PSII }}$ in fact decreased as a function of a time-dependent induction of regulated excitation dissipation Y(NPQ), once cells were at or above a PAR coinciding with saturation of ETR. Instead, the observed increases in ETR under extended high light were explained by an increase in the rate of PSII reopening, i.e. $\mathrm{Q}_{\mathrm{A}}{ }^{-}$oxidation. This acceleration of electron transport was strictly light dependent and relaxed within seconds after a return to low light or darkness. The time-dependent nature of ETR upregulation and regulated NPQ induction was verified using induction-recovery curves. Our findings show a time-dependent induction of excitation dissipation, in parallel with very rapid photoacclimation of electron transport, which combine to make ETR independent of short-term changes in PAR. This supports a selective advantage for these diatoms when exposed to fluctuating light in their environment.
\end{abstract}

Keywords Photoacclimation $\cdot$ Diatom photophysiology $\cdot$ Downregulation $\cdot$ Haslea $\cdot$ Electron transport rate

R. Perkins and C. Williamson share first authorship.

Electronic supplementary material The online version of this article (https://doi.org/10.1007/s11120-018-0508-x) contains supplementary material, which is available to authorised users.

\section{R. Perkins}

PerkinsR@cf.ac.uk

1 School of Earth and Ocean Sciences, Cardiff University, Park Place, Cardiff, Wales CF10 3AT, UK

2 Schools of Biological and Geographical Sciences, University of Bristol, 12 Berkeley Square, Bristol BS8 1SS, UK

3 UMI 3376 Takuvik, CNRS/Université Laval, Département de Biologie-Pavillon Alexandre Vachon, Québec, QC G1V 0A6, Canada

4 Mer-Molécules-Santé (MMS), FR CNRS 3473 IUML, Le Mans Université, Av. O. Messiaen, 72085 Le Mans Cedex 9, France

5 Department of Biology, Mount Allison University, Sackville, NB E4L3M7, Canada

\section{Introduction}

Variability in the light environment is likely a key parameter dictating diatom species distribution (Lavaud et al. 2007), and hence to our understanding of the ability of diatoms to acclimate to changes in their light environment. Formerly considered to be restricted to a single species, Haslea ostrearia, the Haslea genus of pennate diatoms has recently been elucidated to comprise $>20$ species, occurring globally throughout temperate to tropical ecosystems (Gastineau et al. 2014). This is typical of many taxa of diatoms, with apparent plasticity of environmental preference (Underwood and Kromkamp 1999; Vanormelingen et al. 2008; Malviya et al. 2016). Species of Haslea diatoms are commonly referred to as "blue" diatoms due to their production of the blue pigment marennine (e.g. Mouget and Tremblin 2002; Mouget et al. 2004, 2005), which has potential for biotechnological exploitation. Therefore, information on light acclimation mechanisms in microalgae is also relevant 
in optimising bioreactor light environments (Eriksen 2008; Carvalho et al. 2011; Sforza et al. 2012).

In this study, we investigated photoacclimation in the form of both non-photochemical downregulation used to dissipate excess excitation and inducible upregulation of electron transport rate (ETR) in two species of Haslea diatoms, $H$. ostrearia and $H$. silbo sp. nov. ined. (here after $H$. silbo). We follow the definition of MacIntyre et al. (2002), that photoacclimation is a plastic response to a change in light field that adjusts the balance between excitation capture and metabolism (MacIntyre et al. 2002). Excitation dissipation refers to photoprotective processes that act to quench excess excitation pressure upon photosystems and dissipate excess absorbed light energy as heat and/or balance excitation energy within the photosynthetic apparatus (Lavaud and Lepetit 2013). Non-photochemical quenching (NPQ) is one form of excitation dissipation that quenches excitation through conversion of a proportion of antennae complex excitation to heat (Lavaud and Goss 2014). NPQ is often separated into regulated (Y[NPQ]) and non-regulated (Y[NO]) components (Klughammer and Schreiber 2008). Regulated excitation dissipation (Klughammer and Schreiber 2008) includes xanthophyll cycle-mediated processes, through the enzymatic de-epoxidation of diadinoxanthin to diatoxanthin (in diatoms) activated in response to light-induced energisation (proton gradient) across the thylakoid membrane (Ting and Owens 1993; Demmig-Adams and Adams 2006; Lavaud and Goss 2014). Diatoms have a high capacity for excitation dissipation through combinations of both regulated and non-regulated mechanisms (Lavaud et al. 2002, 2007; Lepetit et al. 2012). Regulated excitation dissipation as measured in the form of Stern-Volmer NPQ, has been observed to be kinetically biphasic, with Lavaud and Goss (2014) suggesting the de-epoxidation step as the rapid phase of NPQ, followed by dissociation of fucoxanthin-chlorophyll protein complexes from PSII as the slower phase. Upregulation of the relative electron transport rate (rETR) by diatoms has been reported within rapid light curve (RLC) measurements, where an increase in rETR occurred as a result of rapid photoacclimation to the immediate light history applied during the RLC itself (Perkins et al. 2006, 2010; Lefebvre et al. 2011). The mechanisms underlying this rapid photoacclimation are not fully understood (Perkins et al. 2010), in part because rETR is based solely on changes in the quantum yield of the pool of PSII, without considering possible changes in the effective absorption cross section for photochemistry, or changes downstream of electron transport.

We therefore applied a combined RLC and induction-recovery curve methodology (Ralph and Gademann 2005; Serôdio et al. 2005a; Perkins et al. 2006, 2010) while monitoring excitation capture, photochemistry and electron transfer using fast repetition rate fluorescence (FRRf)
(Kolber et al. 1998) to analyse rapid changes in photophysiology and excitation dissipation for the two Haslea species. FRRf single turnover methodology generates fluorescence rise (induction) and reaction centre reopening (relaxation) curves that enable estimation of the effective absorption cross section for photochemistry $\left(\sigma_{\mathrm{PSII}}\right.$ or $\left.\sigma_{\mathrm{PSII}}{ }^{\prime}\right)$; reaction centre connectivity ( $\rho$ or $\rho^{\prime}$ ); the rapid and slow kinetic phase lifetimes for PSII reopening ( $\tau_{1}$ and $\tau_{2}$, respectively), along with the minimum, maximum and operational fluorescence yields commonly used in fluorescence studies: $F_{O}, F_{M}, F_{S}$, $\mathrm{F}_{\mathrm{M}}{ }^{\prime}$ (Kolber et al. 1998). These curve fit parameters then support calculation of absolute, rather than relative, ETR (Suggett et al. 2009; Perkins et al. 2010) and the proportion of PSII reaction centres that are instantaneously closed, referred to as the excitation pressure $\left(1-q_{\mathrm{P}}\right)$ (van Kooten and Snel 1990). RLC techniques typically examine the responses of ETR to sequentially increasing or decreasing light intensities (Perkins et al. 2006, 2010). In the present study, however, we used a non-sequential RLC methodology (Fig. 1) to elucidate photoacclimation processes including upregulation of ETR and downregulation through regulated and non-regulated excitation dissipation, Y(NPQ) and Y(NO), respectively (Klughammer and Schreiber 2008). We hypothesised that (1) upregulation of electron transport would be represented through an increase in ETR as a function of immediate light history, (2) $\sigma_{\mathrm{PSII}}$ would change proportionally with incident light intensity, (3) $\rho$ would decrease as light intensity increased and hence would not counteract a decrease in $\sigma_{\mathrm{PSII}}{ }^{\prime}(\mathrm{Xu}$ et al. 2017), and (4) in order to maximise efficiency of photoprotection, Y(NPQ) would be induced in preference to $\mathrm{Y}(\mathrm{NO})$.

\section{Materials and methods}

Two strains of $H$. ostrearia were isolated from the west coast of France at the Île de Ré and Baie de Bourgneuf in 2015. Cells were collected by micropipette and grown in $f / 2$ medium (Guillard and Ryther 1962). Growth and successful selection of $H$. ostrearia were monitored by light microscopy. A single strain of $H$. silbo was isolated from North Carolina, USA, also in 2015, with cells extracted and grown in the same manner. Once sufficient single species biomass had been obtained, cultures were transferred to the laboratory at Mount Allison University, Sackville, Canada, where all measurements were performed. Cultures were grown in $\mathrm{f} / 2$ medium (Guillard and Ryther 1962) at $20^{\circ} \mathrm{C}$ and at a light intensity of $50 \mu \mathrm{mol}$ photons $\mathrm{m}^{-2} \mathrm{~s}^{-1}$, with a light/dark cycle of $12 \mathrm{~h}: 12 \mathrm{~h}$. Growth of cultures was monitored by following fluorescence emission at $680 \mathrm{~nm}$ using a plate spectrofluorometer (SpectraMax Gemini EM, Molecular Devices, Sunnyvale, USA). 


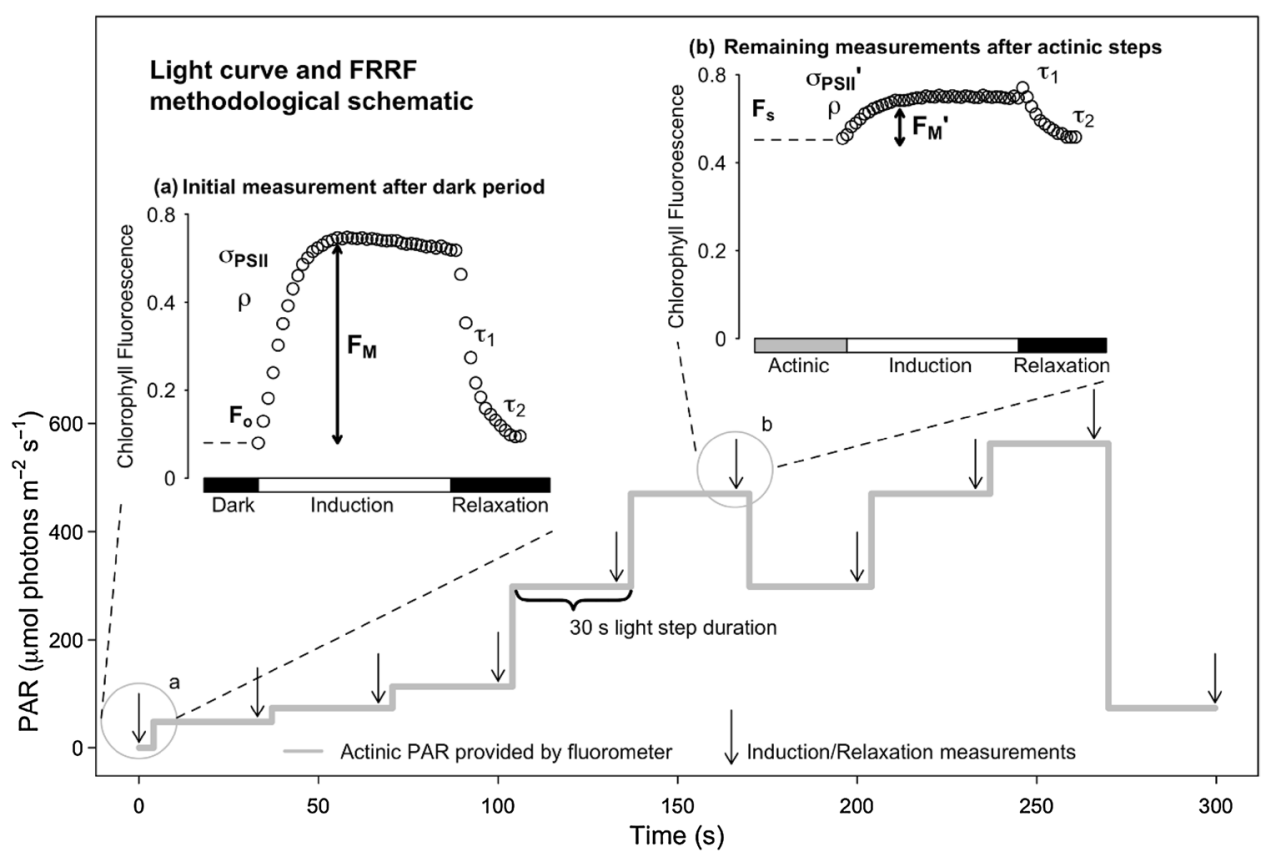

Fig. 1 Non-sequential rapid light response treatment and measuring protocol. On the $Y$ axis we plot the sequence of light levels applied for $30 \mathrm{~s}$ each. Arrowheads show applications of repeated Fast Repetition and Relaxation chlorophyll fluorescence (FRRf) measurements, as demonstrated in annotated inset graphs. The initial FRRf measurement (inset $a$ ) was performed following dark adaptation of samples,

When cultures reached mid-exponential phase, culture subsamples were taken for chlorophyll fluorescence induction measurements, by placing them in a $2 \mathrm{ml}$ cuvette and then dark-adapting them for $\sim 2 \mathrm{~min}$. Samples were then exposed to a series of $30 \mathrm{~s}$ exposures to changing light levels (Fig. 1) to result in a non-sequential rapid light curve (RLC). At the end of each $30 \mathrm{~s}$ exposure we applied a train of 40 blue $(455 \mathrm{~nm})$ flashlets with a duration of $1.2 \mu \mathrm{s}$ each separated by an intervening interval of $1.0 \mu$ s of darkness to induce an FRRf fluorescence induction curve (Kolber et al. 1998), using a Photon Systems Instruments FL3500 fluorometer system (Brno, Czech Republic). This train of 40 blue flashlets cumulatively induced a single turnover of PSII, which reduced $\mathrm{Q}_{\mathrm{A}}$ to $\mathrm{Q}_{\mathrm{A}}{ }^{-}$and thereby photochemically closed PSII. Flashlet intensity was selected to saturate the fluorescence rise within around 30 of 40 flashlets (Laney 2003; Laney and Letelier 2008).

For each FRRf induction curve, data were exported from the FluorWin data capture software to fit a model with four parameters: minimal fluorescence, $\mathrm{F}_{0}$; maximal fluorescence, $\mathrm{F}_{\mathrm{M}}$; effective absorption cross section for PSII photochemistry, $\sigma_{\mathrm{PSII}}$; coefficient of excitonic connectivity $\rho$; and the rapid and slow kinetic phase lifetimes for PSII reopening, $\tau_{1 \text { and }} \tau_{2}$, respectively (Kolber et al. 1998) using the PSIWORX-R package (A. Barnett, sourceforge.net) (Murphy et al. 2016; Ni et al. 2016). For each measurement we applied an FRRf induction with all subsequent measurements (inset $b$ ) performed following $30 \mathrm{~s}$ at respective light levels. For each measurement, a fast fluorescence induction and relaxation measurement were applied both in the presence of background actinic light (insets), and following $1 \mathrm{~s}$ darkness (not shown) immediately after exposure to the preceding light step, to allow reopening of photosystem II

before and then again after a $1 \mathrm{~s}$ period of darkness to allow PSII to reopen after illumination. We thus determined in the dark $\mathrm{F}_{0}, \mathrm{~F}_{\mathrm{M}}, \sigma_{\mathrm{PSII}}, \rho$; under actinic light $\mathrm{F}_{\mathrm{S}}, \mathrm{F}_{\mathrm{M}}{ }^{\prime}, \sigma_{\mathrm{PSII}}{ }^{\prime} \rho^{\prime}$; and following $1 \mathrm{~s}$ of darkness after actinic light $\mathrm{F}_{0}{ }^{\prime} 1 \mathrm{~s}, \mathrm{~F}_{\mathrm{M}}{ }^{\prime} 1 \mathrm{~s}$, $\rho^{\prime} 1 \mathrm{~s}, \sigma_{\mathrm{PSII}}{ }^{\prime} 1 \mathrm{~s}$. Note that the prime superscript indicates that the parameter was measured under actinic light whereas '1s indicates a measurement taken from cells in instantaneous darkness immediately following actinic light.

We then estimated $\mathrm{F}_{0}{ }^{\prime}$ as:

$\mathrm{F}_{0}{ }^{\prime}=\mathrm{F}_{01 \mathrm{~s}}^{\prime} \times\left\{1-\left[\left(\mathrm{F}_{\mathrm{M}}{ }_{1 \mathrm{~s}}^{\prime}-\mathrm{F}_{\mathrm{M}}{ }^{\prime}\right) / \mathrm{F}_{\mathrm{M}}{ }_{1 \mathrm{~s}}\right]\right\}$ (Oxborough and Baker 1997).

We estimated the coefficient of photochemical quenching $\left(\mathrm{q}_{\mathrm{p}}\right)$ :

$\mathrm{q}_{\mathrm{P}}=\left(\mathrm{F}_{\mathrm{M}}{ }^{\prime}-\mathrm{F}_{\mathrm{S}}\right) /\left(\mathrm{F}_{\mathrm{M}}{ }^{\prime}-\mathrm{F}_{0}{ }^{\prime}\right)($ Kramer et al. 2004).

We estimated the yield of non-photochemical quenching (Y[NPQ]):

$\mathrm{Y}(\mathrm{NPQ})=\mathrm{F}_{\mathrm{S}} / \mathrm{F}_{\mathrm{M}}{ }^{\prime}-\mathrm{F}_{\mathrm{S}} / \mathrm{F}_{\mathrm{M}} \quad$ (Klughammer and Schreiber 2008),

and the yield of non-regulated excitation dissipation $(\mathrm{Y}[\mathrm{NO}])$ :

$\mathrm{Y}(\mathrm{NO})=\mathrm{F}_{\mathrm{s}} / \mathrm{F}_{\mathrm{M}}$ (Klughammer and Schreiber 2008).

For plotting the non-sequential light curves, we calculated the ETR as:

$\mathrm{ETR}=\mathrm{E} \times \sigma_{\mathrm{PSII}}{ }^{\prime} \times \mathrm{Y}(\mathrm{PSII}) /\left(\left(\mathrm{F}_{\mathrm{M}}-\mathrm{F}_{0}\right) / \mathrm{F}_{\mathrm{M}}\right)$, 
where $\mathrm{Y}(\mathrm{PSII})$ is the quantum efficiency of PSII calculated as $\left(\mathrm{F}_{\mathrm{M}}{ }^{\prime}-\mathrm{F}_{\mathrm{S}}\right) / \mathrm{F}_{\mathrm{M}}{ }^{\prime}$.

This is modified from Suggett et al. (2009) as we did not include $\mathrm{n}_{\text {PSII }}$ (usually set to 0.002) and we expressed ETR as e- $\mathrm{PSII}^{-1} \mathrm{~s}^{-1}$. In some cases our light response curve extended to actinic light levels high enough to suppress the remaining variable fluorescence to small values when FRRf inductions were performed in the presence of actinic light. Statistical analyses and plotting were performed using $\mathrm{R}$ Version 3.3.2 (R Core Team 2016) with the package 'minpack.lm' (Timur et al. 2016).

In order to determine the interaction of regulated and non-regulated excitation dissipation, regulated excitation dissipation Y(NPQ) was inhibited in replicates treated with DL-dithiothreitol (DTT, Bioshop), which inhibits xanthophyll cycling through suppression of the de-epoxidation of diadinoxanthin to diatoxanthin (Bilger and Björkman 1990; Lavaud et al. 2002; Ni et al. 2016). DTT was prepared as fresh $5 \mathrm{mM}$ stock on each day of measurements dissolved in ethanol. $20 \mu \mathrm{L}$ aliquots of the stock were added to $2 \mathrm{ml}$ of culture to produce a final concentration of $5 \mu \mathrm{M}$ which was reported to fully inhibit Stern-Volmer non-photochemical quenching (NPQ) (Ni et al. 2016). These treatments were then examined using the same non-sequential RLC as described above, with five replicate RLCs for each Haslea strain.

Finally, the same strains of Haslea were exposed to induction-recovery curves whereby subsamples from each culture, as described above were exposed to actinic light (induction phase) prior to a dark recovery period. Two light levels were used, 300 and $600 \mu \mathrm{mol}$ photons $\mathrm{m}^{-2} \mathrm{~s}^{-1}$ to represent comparatively lower and higher light stress and hence different levels of hypothesised upregulation of ETR and induction of excitation dissipation. The induction phase lasted $1200 \mathrm{~s}(20 \mathrm{~min})$ and was followed by a dark recovery phase of $900 \mathrm{~s} \mathrm{(15} \mathrm{min),} \mathrm{to} \mathrm{investigate} \mathrm{the} \mathrm{time} \mathrm{course} \mathrm{of}$ induction and reversal of upregulation and excitation dissipation, respectively. Measurements were made using the FRRf fluorometer and data analysis procedures as described for the RLCs described above.

\section{Results}

All three Haslea strains showed similar patterns of rapid photoacclimation in ETR (Fig. 2a) and photosystem II quantum efficiency (Y(PSII); Fig. 2b) during non-sequential rapid light curves (RLCs). ETR increased for the first three increasing light steps up to PAR $114 \mu \mathrm{mol} \mathrm{m} \mathrm{m}^{-2} \mathrm{~s}^{-1}$, before a downward curvature showing supersaturation for the fourth and fifth light curve steps up to a PAR of $470 \mu \mathrm{mol} \mathrm{m}^{-2} \mathrm{~s}^{-1}$, $180 \mathrm{~s}$ into the light curve. Subsequently, during the remainder of the non-sequential light curve steps, ETR and Y(PSII) departed from proportional changes with PAR. When PAR was lowered from 470 back to $300 \mu \mathrm{mol} \mathrm{m}^{-2} \mathrm{~s}^{-1}$, ETR and Y(PSII) increased to values greater than previously measured at this light level during the initial incrementally increasing PAR phase of the light curve. Subsequently, when PAR was reincreased back to 470 and on to $540 \mu \mathrm{mol} \mathrm{m}^{-2} \mathrm{~s}^{-1}$, ETR and Y(PSII) increased to values greater than those measured previously, and hence greater than the values of ETR at which the light curves had previously saturated (Fig. 2a). Thus, ETR at a given high light level increased in response to the light history during the short $30 \mathrm{~s}$ light curve steps of the RLC. After 270 s, PAR was lowered to the same level as the second light step of the RLC (i.e. growth irradiance, $74 \mu \mathrm{mol} \mathrm{m} \mathrm{m}^{-2} \mathrm{~s}^{-1}$ ), whereby ETR decreased to a value slightly lower than the original value initially measured at this light level, and Y(PSII) went to a value that was slightly lower than the original value. During the induction phase of the induction-recovery curves (Fig. 3), ETR increased for the lower light treatment (Fig. 3a) and for two of the three strains in the high light treatment (Fig. 3b), with the exception of $H$. silbo, attributable to an increase in Y(PSII) over time at elevated light (Fig. 3c,d).

All three strains of Haslea showed similar excitation dissipation responses to changing light, with non-regulated excitation dissipation $\mathrm{Y}(\mathrm{NO})$ (Fig. 4a) increasing from $\sim 0.4$ in darkness to $\sim 0.85$ as PAR increased for the first four sequential RLC steps up to $300 \mu \mathrm{mol}$ photons $\mathrm{m}^{-2} \mathrm{~s}^{-1}$. Coincident with the onset of saturation of ETR $(\sim 300 \mu \mathrm{mol}$ photons $\mathrm{m}^{-2} \mathrm{~s}^{-1}$; Fig. 2a), regulated, energy-dependent, excitation dissipation Y(NPQ) was induced (Fig. 4b), with a concomitant decline in $\mathrm{Y}(\mathrm{NO})$ (Fig. 4a). Once induced, $\mathrm{Y}(\mathrm{NPQ})$ increased progressively with time under high light, as opposed to reflecting patterns in PAR during the non-sequential phase of the RLC. At the end of the RLC, $\mathrm{Y}(\mathrm{NPQ})$ remained elevated whilst $\mathrm{Y}(\mathrm{NO})$ declined to less than initial values, despite the return to growth irradiance. This time-dependent induction of Y(NPQ) was confirmed with induction-recovery curves (Fig. 5), whereby decreases in $\mathrm{Y}(\mathrm{NO})$ in both lower and higher light induction phases (Fig. 5 a, b) paralleled steady induction of Y(NPQ) (Fig. 5c, d). Note that in both light treatments, incomplete reversal of $\mathrm{Y}(\mathrm{NPQ})$ during the dark recovery phase was apparent. In notable contrast, RLC treatments with DTT addition showed a steady increase in $\mathrm{Y}(\mathrm{NO})$ to saturation at $\sim 1$ during the first four incremental increases in PAR (Fig. 4c), whilst Y(NPQ) decreased (Fig. 4d); the latter a function of increasing $\mathrm{F}_{\mathrm{M}}$ ' (data not shown) above initial values in the dark, suggesting residual NPQ at the start of the RLC. DTT treatment thus served to suppress Y(NPQ) induction, and consequently $\mathrm{Y}(\mathrm{NO})$ was not inhibited.

The cross-sectional absorbance of PSII, $\sigma_{\text {PSII }}$, decreased throughout the course of RLCs (Fig. 6.), in parallel with a decrease in reaction centre connectivity, $\rho$ (Supplementary 
Fig. 2 Photosystem II (a) ETR and (b) quantum yield (Y) over the course of non-sequential rapid light curves for $H$. ostrearia strain Île de Ré $(H$. ost. IdR), H. ostrearia strain Baie de Bourgneuf (H. ost. $B d B$ ), and $H$. silbo (mean $\pm \mathrm{SE}$, $n=3$ ). Background trace (light blue line) shows the respective light levels (right axes) applied at each light step

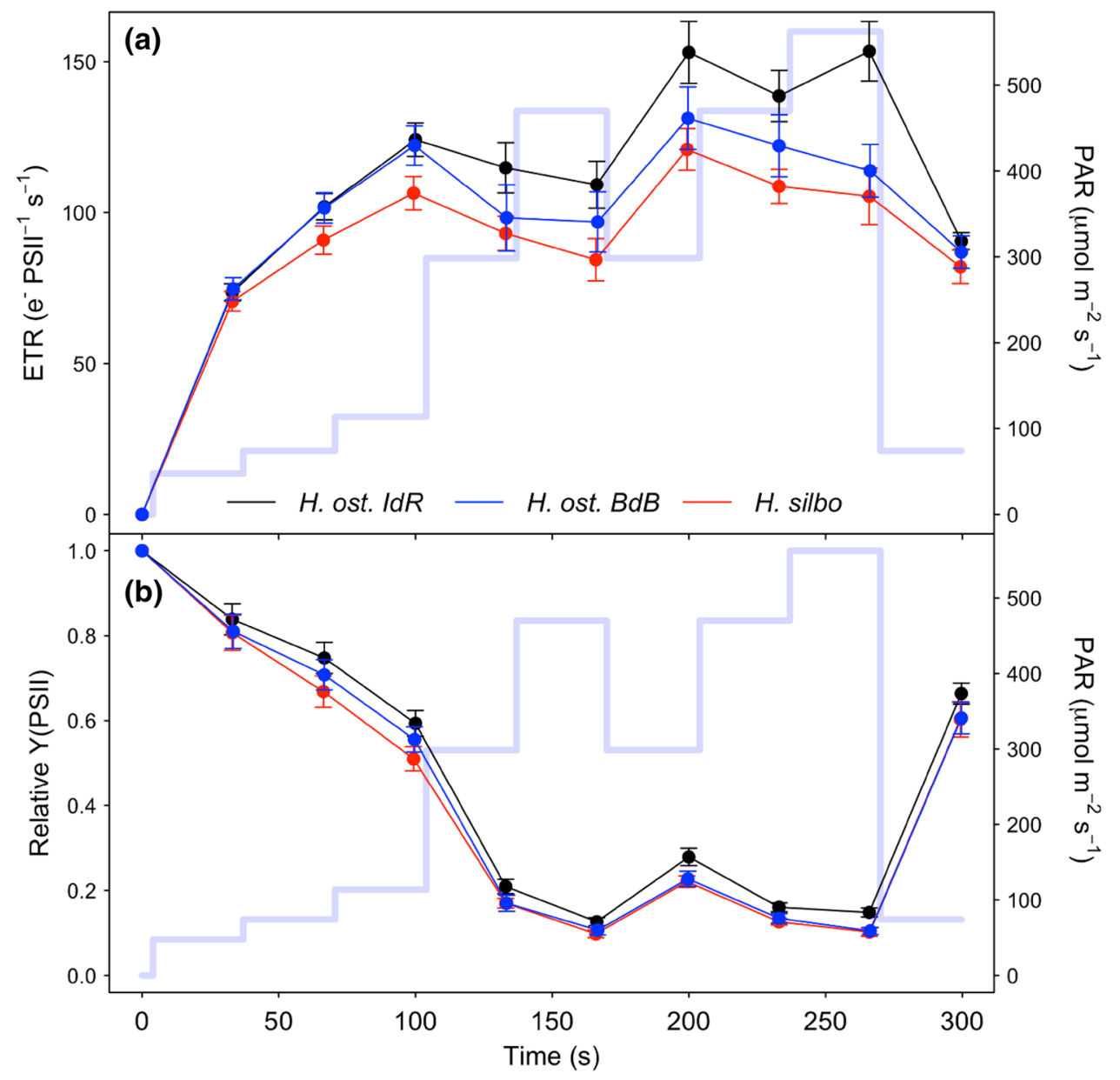

Fig. S1), as light level and reaction centre closure (1-qP) increased. Across all RLC data, $\sigma_{\mathrm{PSII}}$ showed a negative relationship to Y(NPQ) (Supplementary Fig. S2a), whereas no clear relationship was apparent between $\sigma_{\mathrm{PSII}}{ }^{\prime}$ and $\mathrm{Y}(\mathrm{NO})$ (Supplementary Fig. S2b), nor to the sum of NPQ parameters (Supplementary Fig. S2c). Across all induction/recovery curve data, normalised $\sigma_{\mathrm{PSII}}$ ' decreased as a linear function of increasing Y(NPQ) $\left(R^{2}=0.43, P<0.001, n=48\right.$, Fig. Supplementary Fig. S3); however, this response was less than unity (slope $=-0.65$ ), indicating that increases in Y(NPQ) did not drive proportional decreases in $\sigma_{\mathrm{PSII}}{ }^{\prime}$. Overall, with Y(NPQ) induction over RLCs, the time-dependent upregulation of ETR was not driven by corresponding increases in $\sigma_{\mathrm{PSII}}$ ' nor $\rho^{\prime}$, and hence another process was responsible for the increases in Y(PSII) and ETR.

With exposure to increasing PAR during initial RLC steps up to $470 \mu \mathrm{mol}$ photons $\mathrm{m}^{-2} \mathrm{~s}^{-1}$, reaction centre opening lifetimes $\left(\tau_{1}\right)$ measured in the light increased from $\sim 500$ to $\sim 1800 \mu$ s as excitation pressure increasingly exceeded downstream electron transport (Fig. 7a). Upon subsequent decrease in PAR to $300 \mu$ mol photons $\mathrm{m}^{-2} \mathrm{~s}^{-1}, \tau_{1}$ decreased to just $1000 \mu \mathrm{s}$, below previous values measured at the same PAR. Thereafter, $\tau_{1}$ remained accelerated despite subsequent reexposure to high PAR, indicating that the initial exposure to high light had induced process(es) that accelerated electron transport away from PSII. This mechanism was retained whilst samples remained under high light exposure, but was lost when samples were returned to growth irradiance during the final RLC step. Notably, $\tau_{1}$ lifetimes measured after only $1 \mathrm{~s}$ of darkness (Fig. $7 \mathrm{~b}$ ) remained stable at $\sim 500 \mu$ s throughout the duration of non-sequential light response treatments and thus dynamism in $\tau_{1}$ appeared strictly dependent upon exposure to high illumination. Under induction/recovery curves (Fig. 8), again $\tau_{1}$ generally decreased in a timedependent manner following exposure to induction phase irradiances, with $H$. silbo remaining an exception under high light, while stable $\tau_{1}$ lifetimes were apparent at $\sim 500 \mu \mathrm{s}$ when measured after $1 \mathrm{~s}$ darkness. Overall, examination of the relationship between Y(PSII) and $\tau_{1}$ across all datasets revealed a significant negative relationship $\left(R^{2}=0.76\right.$, $P<0.0001, n=78$, Supplementary Fig. S4), indicating that shorter lifetimes for $\mathrm{Q}_{\mathrm{A}}$ oxidation, and hence more rapid oxidation on the acceptor side of photosystem II (PSII), drove higher quantum efficiencies of PSII, which in turn supported the light history-dependent acceleration of ETR (Fig. 2). 


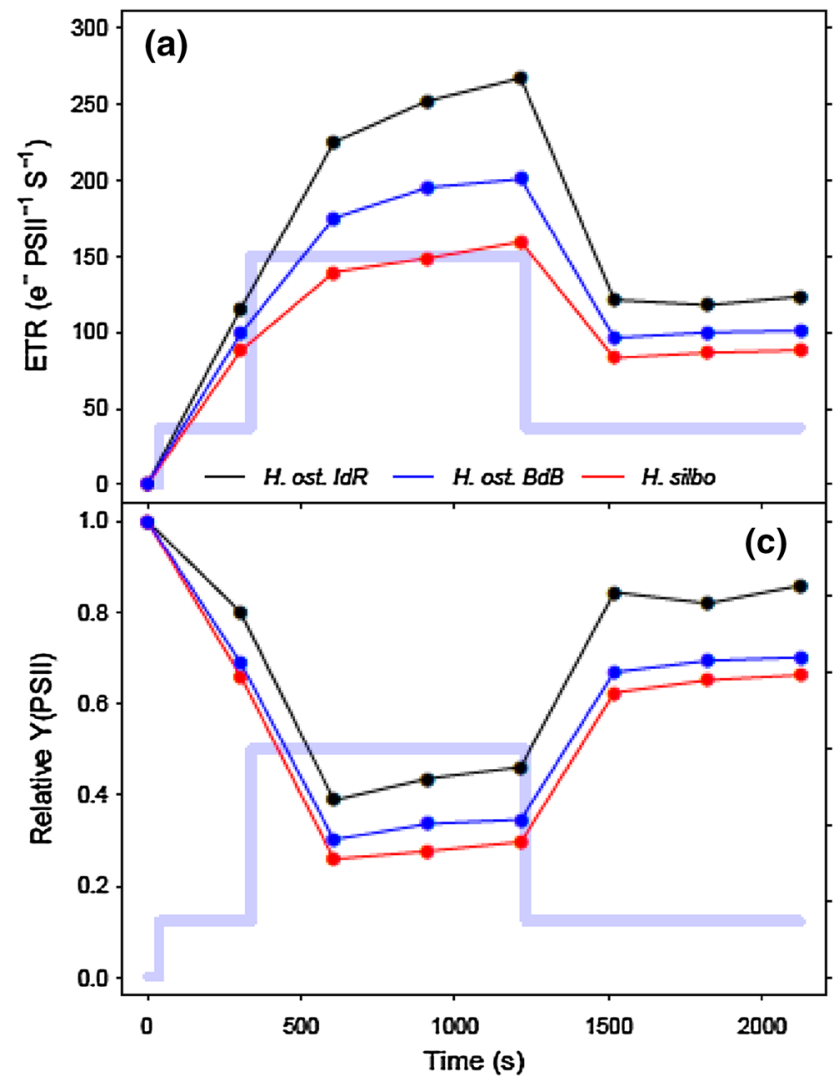

Fig. 3 Photosystem II (a, b) ETR and (c, d) quantum efficiency (Y) over the course of induction and recovery curves at low light (left column) and high light (right column) for $H$. ostrearia strain Ile de Ré (H. ost. IdR), H. ostrearia strain Baie de Bourgneuf (H. ost. BdB),

\section{Discussion}

Haslea diatoms showed rapid photoacclimation dependent upon their immediate light history. ETR that initially saturated during incrementally increasing light steps of RLCs was subsequently upregulated through stepped changes in light intensity. Upregulation of relative ETR (rETR, in the absence of measurement of light absorption) has previously been reported in diatoms, but was assumed to be a light proportional response (e.g. Perkins et al. 2006). Indeed, an upregulation of ETR may have contributed to failure of light curve saturation during a number of previous studies, including those performed in situ with diatom-dominated estuarine biofilms (Perkins et al. 2002), cyanobacterial cryoconite communities (Perkins et al. 2017), or during ex situ assessment of Streptophyte microalgae (Yallop et al. 2012), although the role of cell motility and forms of physiological downregulation through use of tertiary pigments are also known contributing factors in these studies. Similarly timedependent induction of excitation dissipation and/or nonphotochemical quenching has also been reported in situ for microalgae (Perkins et al. 2017). Increases in maximum ETR

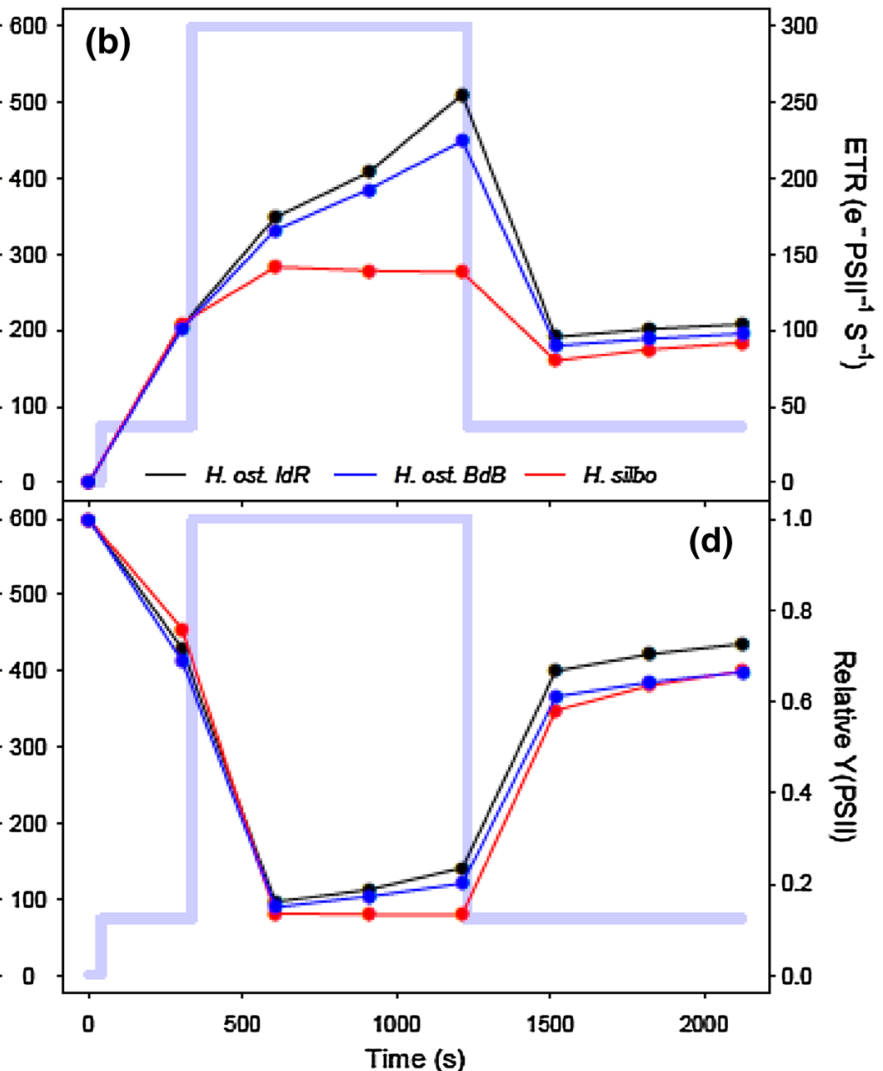

and $H$. silbo sp. nov. ined.. Background trace (light blue line) shows the respective light levels (central axes, PAR $\mu$ mol photons $\mathrm{m}^{-2} \mathrm{~s}^{-1}$ ) applied at each light step

with extended illumination during RLCs has previously been reported in vascular plants (White and Critchley 1999) and chlorophyte macroalgae (Ihnken et al. 2010). However, the present study is the first to investigate mechanisms driving such upregulation, and to highlight the time-dependent nature of this process, concomitant with the induction of regulated excitation dissipation.

The high light upregulation of ETR identified in this study was not explicable in terms of a change in $\sigma_{\text {PSII }}{ }^{\prime}$, which actually decreased in response to progressive induction of regulated excitation dissipation, Y(NPQ), over the same time periods. Additionally, reaction centre excitonic connectivity ( $\rho$, which actually decreased) did not serve to offset the decreases in $\sigma_{\mathrm{PSII}}{ }^{\prime}$. Instead, the increases in ETR were explicable by a decrease in the $\tau_{1}$ lifetime for reopening of PSII. This acceleration of downstream electron transport was dependent upon exposure to high light, and relaxed within $1 \mathrm{~s}$ of darkness, or under lower light. We suspect that this acceleration reflects the opening of additional electron flux(es) when the plastoquinone (PQ) becomes reduced under high excitation pressure. The patterns of upregulated ETR and Y(PSII), in response to 


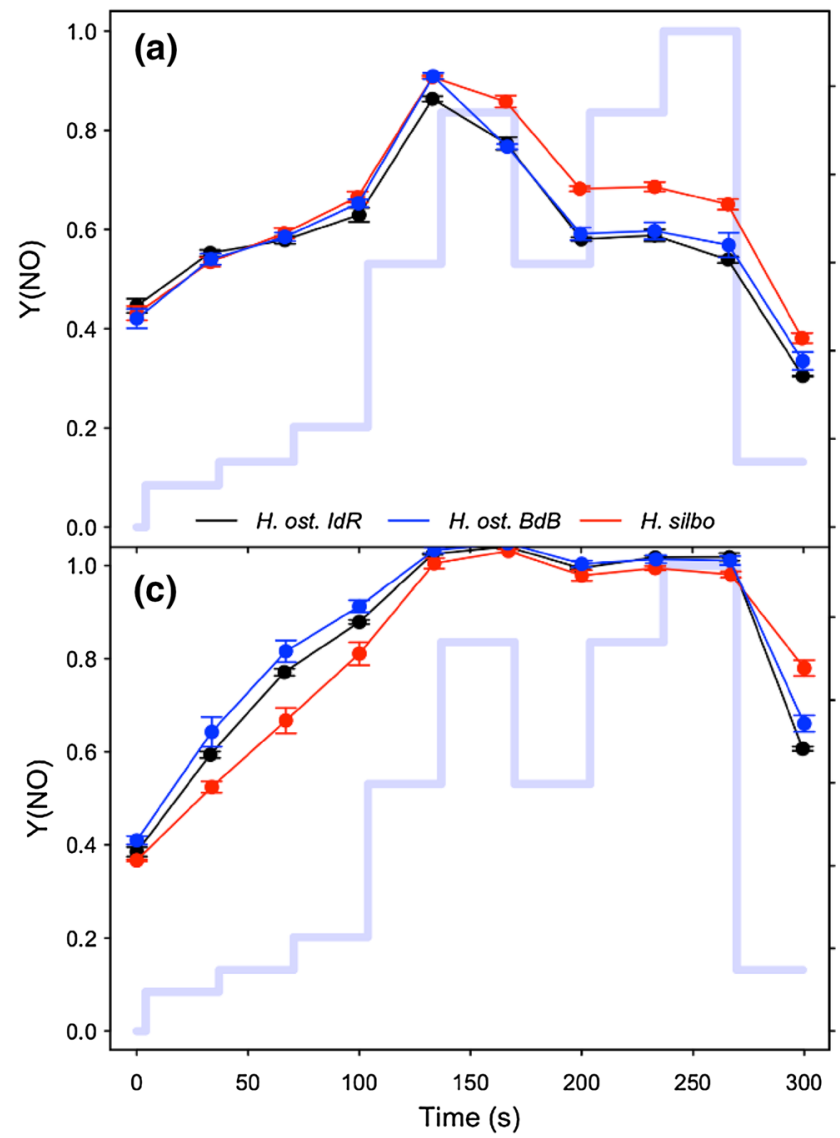

Fig. 4 Excitation dissipation responses of $H$. ostrearia strain Île de Ré (H. ost. IdR), H. ostrearia strain Baie de Bourgneuf (H. ost. BdB), and $H$. silbo sp. nov. ined., during non-sequential rapid light curves $($ mean \pm SE, $n=3)$. Non-regulated (Y $[\mathrm{NO}], \mathbf{a}$ and $\mathbf{c})$ and regulated

preceding exposure to high light can therefore be explained by the increased rate of electron transport away from PSII, detected by analyses of PSII reopening after a single turnover saturating flashlet (Fig. 1) (McCauley and Melis 1987; Cao and Govindjee 1990; Kolber et al. 1998). This reopening can be fitted with 2 or 3 kinetic phases, of which the quickest $\left(\tau_{1}\right)$, with a lifetime on the order of $\sim 500 \mu$ s (Cao and Govindjee 1990), reflects electron flow from $\mathrm{Q}_{A}{ }^{-}$to $\mathrm{Q}_{B}$ in PSII centres that already carry a bound plastoquinone $\left(\mathrm{Q}_{\mathrm{B}}\right)$ at the time of the flashlet. Such centres can pass electrons from $\mathrm{Q}_{\mathrm{A}}^{-}$, reduced during the single turnover flashlet, to the bound $\mathrm{Q}_{\mathrm{B}}$ in a rapid electron transfer, giving a rapid photochemical reopening (Fig. 1). Our data show a decrease in the lifetime for the rapid oxidation of $\mathrm{Q}_{\mathrm{A}}{ }^{-}$through electron flow to $\mathrm{Q}_{\mathrm{B}}\left(\tau_{1}\right)$ dependent upon short-term light history. Importantly, this increase in rate of electron transport, once induced, was retained even when the applied actinic light level was decreased, so long as light remained above the initial level of light saturation. We hypothesise either upregulation of ETR through an increase in linear electron transport and in turn increased productivity, or alternatively

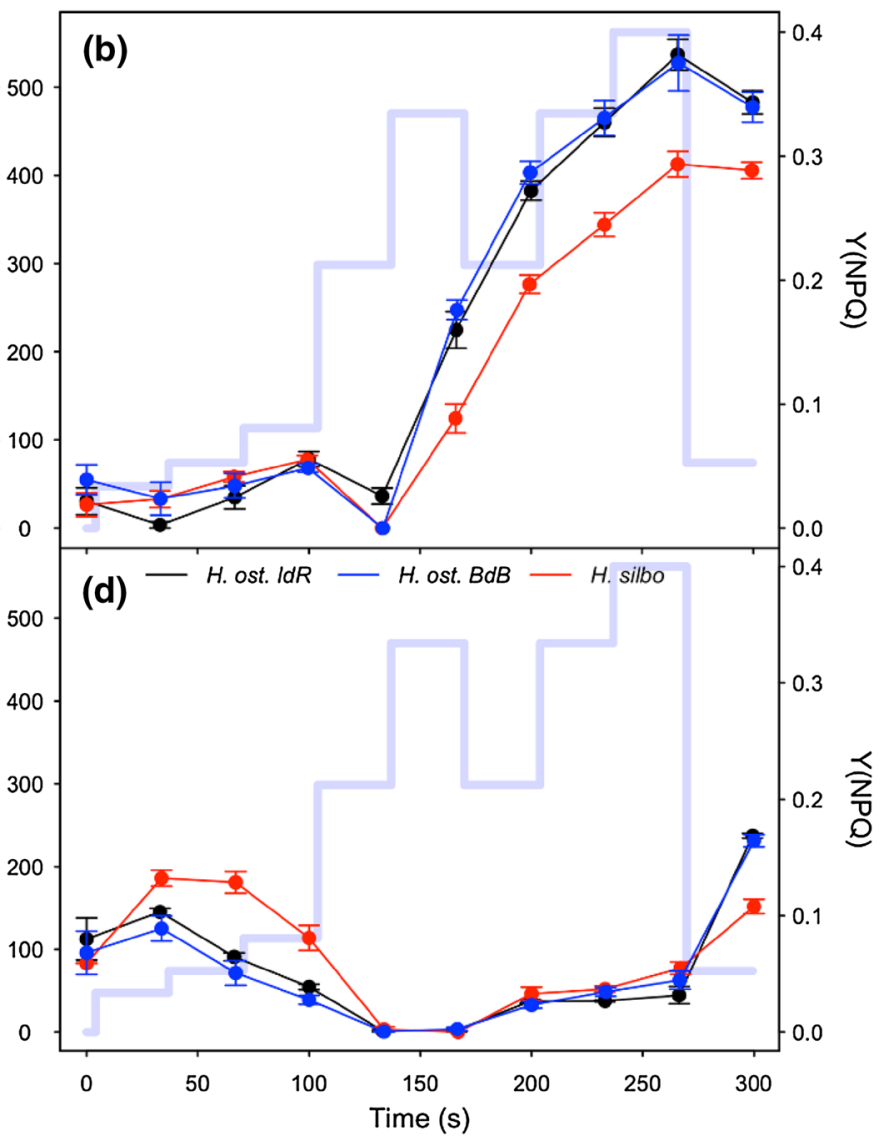

(Y $[N P Q], b$ and d) excitation dissipation components are shown, for untreated samples (a and b), and samples treated with DTT (c and d). Background trace (light blue line) shows the respective light levels (middle axes, PAR $\mu \mathrm{mol}$ photons $\mathrm{m}^{-2} \mathrm{~s}^{-1}$ ) applied at each light step

a photoprotective upregulation through the use of alternative electron acceptor(s), e.g. oxygen-dependent electron transport. Due, however, to the rapid reversibility of the acceleration in $\tau_{1}$, we suspect photoprotective flow(s) to alternative acceptors, in particular oxygen-dependent electron transport, rather than increased production and utilisation of reducing agents further downstream. Either process, however, demonstrates a competitive advantage in diatoms to rapidly upregulate photochemistry either as a form of photoprotection when exposed to high light, or as a real increase in photosynthetic productivity to exploit high light (Curien et al. 2016; Gerotto et al. 2016; Ilík et al. 2017).

Downregulation of PSII was monitored through both nonregulated $\mathrm{Y}(\mathrm{NO})$ and regulated $\mathrm{Y}(\mathrm{NPQ})$, energy dissipation. To minimise damaging impacts of high light exposure, a low ratio of $\mathrm{Y}(\mathrm{NO})$ to $\mathrm{Y}(\mathrm{NPQ})$ may be beneficial (Klughammer and Schreiber 2008). In this study, we observed initial induction of $\mathrm{Y}(\mathrm{NO})$ at low light intensities, but once a threshold in light intensity, or possibly light dose, was achieved which corresponded to initial saturation of ETR, regulated Y(NPQ) was induced and $\mathrm{Y}(\mathrm{NO})$ decreased. Similar patterns have 


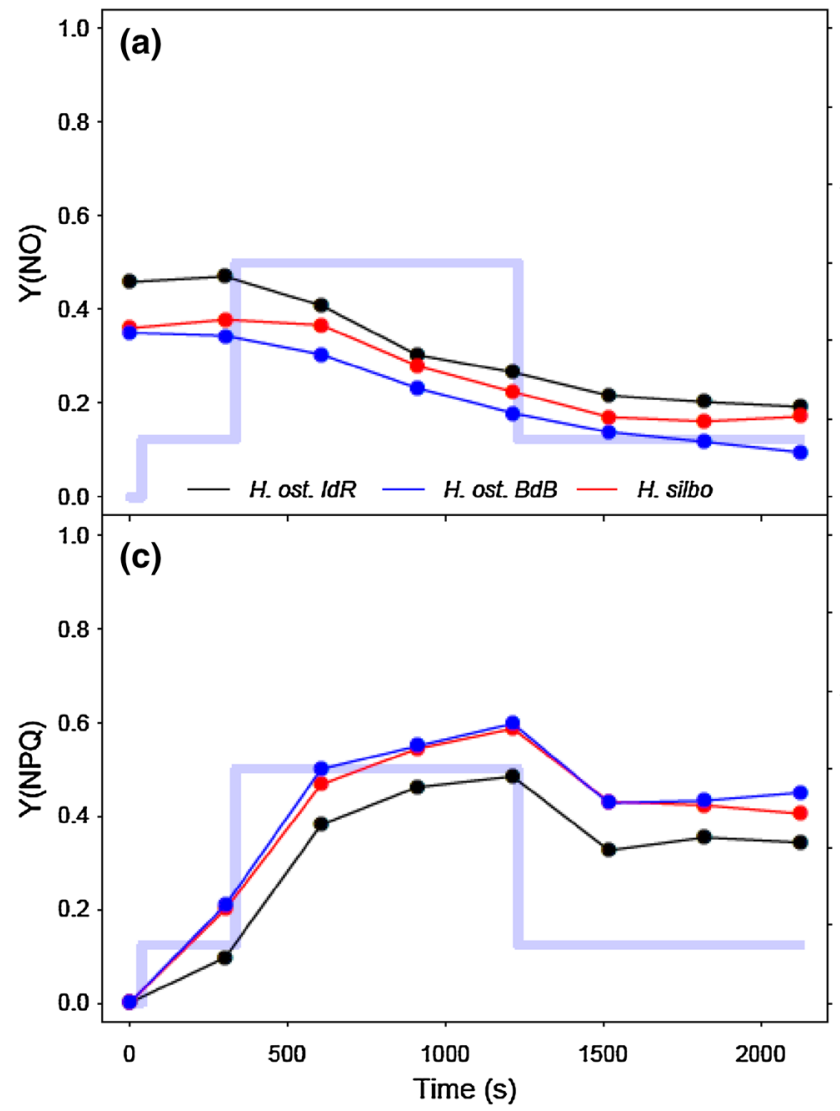

Fig. 5 Excitation dissipation responses of $H$. ostrearia strain Île de Ré (H. ost. IdR), H. ostrearia strain Baie de Bourgneuf (H. ost. BdB), and $H$. silbo sp. nov. ined., during low light (left column) and high light (right column) induction and recovery curves. Both non-regu-

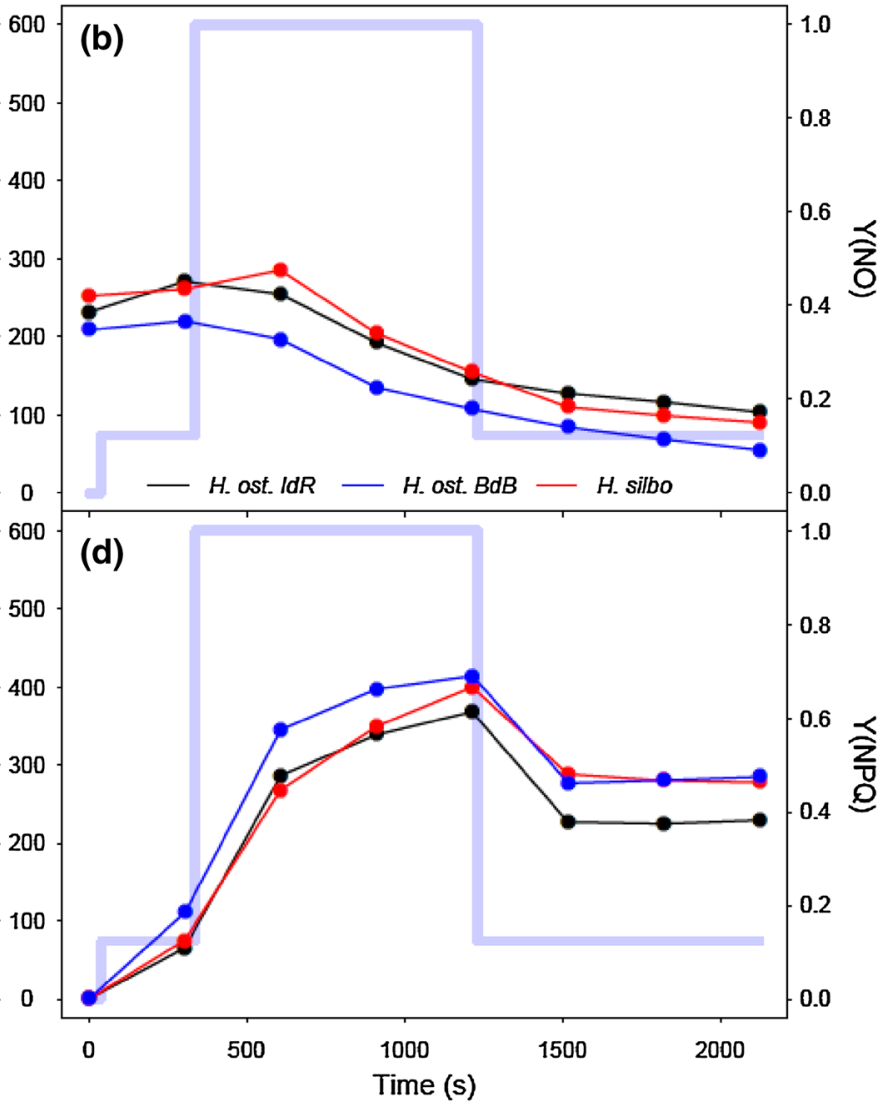

lated (Y[NO], a, b) and regulated (Y[NPQ], c, d) excitation dissipation components are shown. Background trace (light blue line) shows the respective light levels (central axes, PAR $\mu$ mol photons $\mathrm{m}^{-2} \mathrm{~s}^{-1}$ ) applied at each light step
Fig. 6 Photosystem II (PSII) effective absorption cross section $\left(\sigma_{\mathrm{PSII}}, \sigma_{\mathrm{PSII}}\right)$ of $H$. ostrearia strain Île de Ré (H. ost. IdR), H. ostrearia strain Baie de Bourgneuf (H. ost. BdB), and $H$. silbo, during non-sequential rapid light curves (mean $\pm \mathrm{SE}$, $n=3$ ). Background trace (light blue line) shows the respective light levels (right axes) applied at each light step

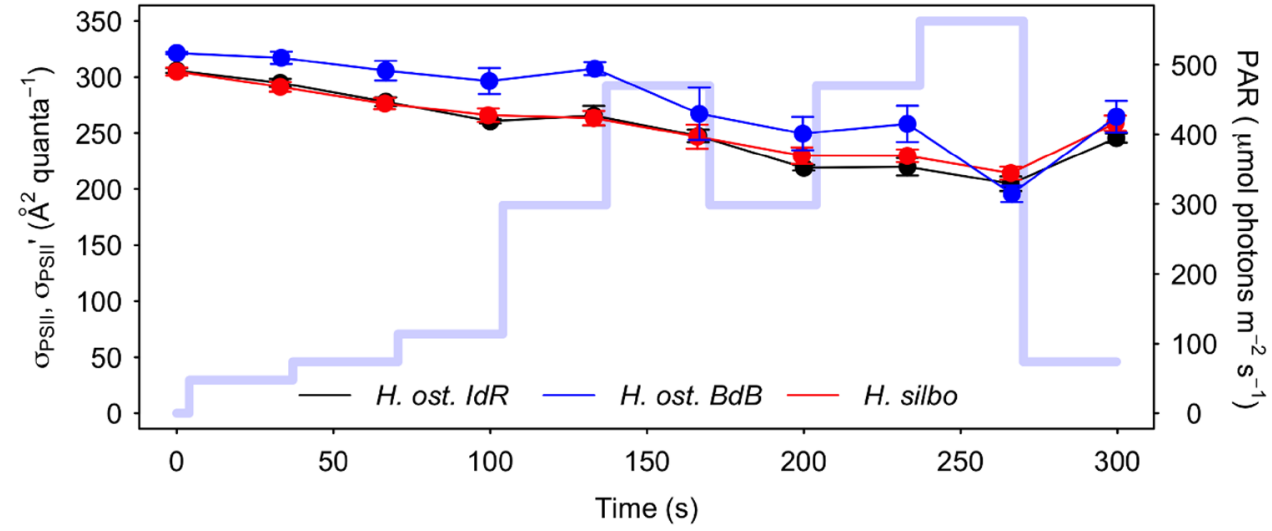

been observed in other eukaryotic microalgae, but not in photosynthetic prokaryotes (Xu et al. 2017). The threshold for $\mathrm{Y}(\mathrm{NPQ})$ induction has been suggested to correspond to an excitation pressure $\left(1-\mathrm{q}_{\mathrm{P}}\right)$ of approximately $45 \%$ (Ruban et al. 2004; Lavaud et al. 2007), but this does not appear to be a constant for all diatoms (Lavaud et al. 2016). It would seem likely that previous culture light history will at least in part determine the threshold for the induction of regulated downregulation and the rate of induction above a threshold (Lavaud et al. 2016), as reported by Xu et al. (2017). In this study, above $\sim 305 \mu \mathrm{mol} \mathrm{m} \mathrm{m}^{-2} \mathrm{~s}^{-1}$ PAR, Y(NPQ) induction became time dependent rather than light intensity dependent. Lavaud and Goss (2014) provide a model for non-photochemical quenching in diatoms, proposing a 
Fig. $7 \tau_{1}$ reaction centre opening $\left(\mathrm{Q}_{\mathrm{A}}\right.$ - oxidation) lifetimes for $H$. ostrearia strain Île de Ré (H. ost. IdR), H. ostrearia strain Baie de Bourgneuf (H. ost. $B d B$ ), and $H$. silbo, measured during non-sequential rapid light curves (a) in the presence of actinic light at the end of each $30 \mathrm{~s}$ light step, and (b) following $1 \mathrm{~s}$ darkness immediately after exposure to each preceding light step (mean $\pm \mathrm{SE}$, $n=3$ ). Background trace (light blue line) shows the respective light levels (right axes) applied at each light step

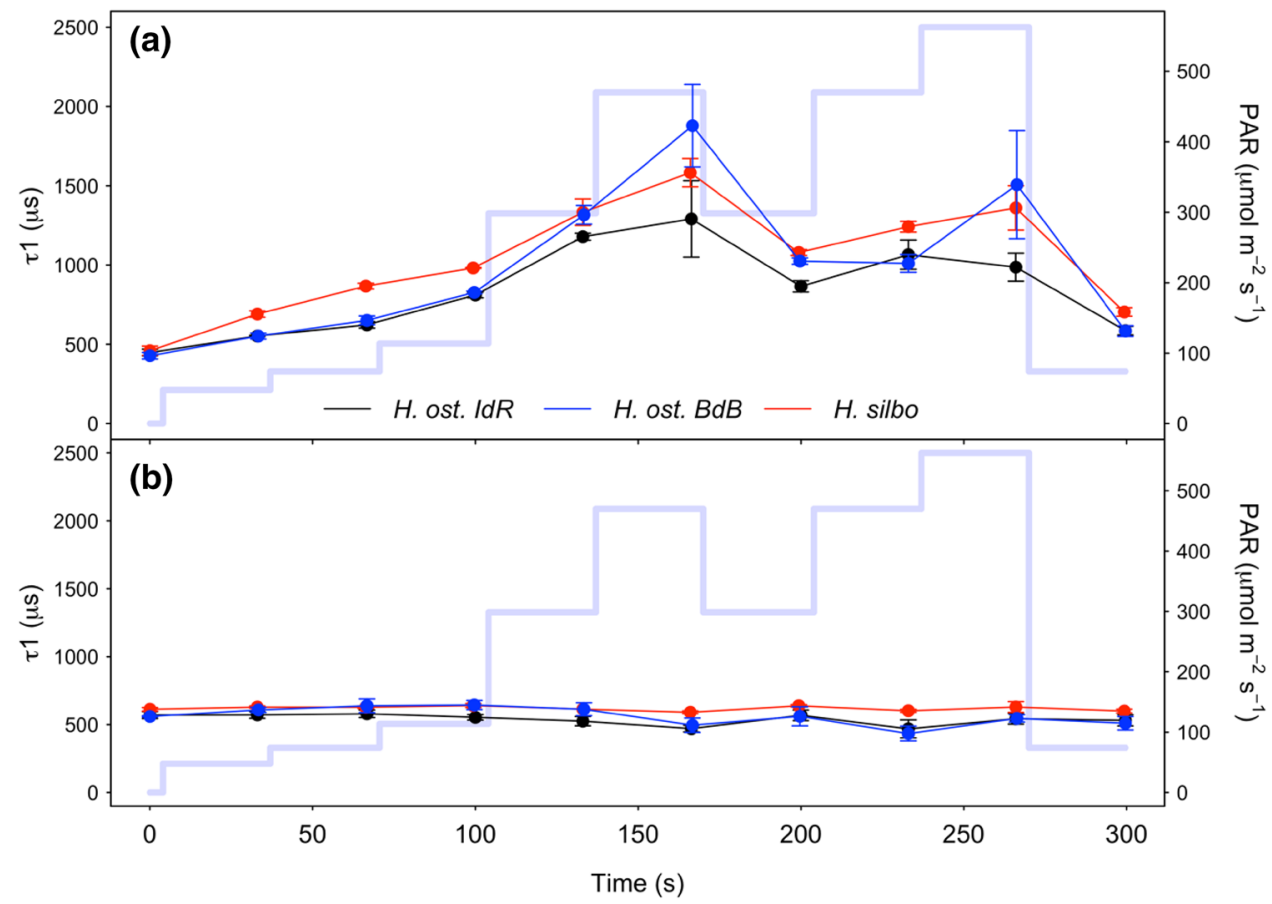

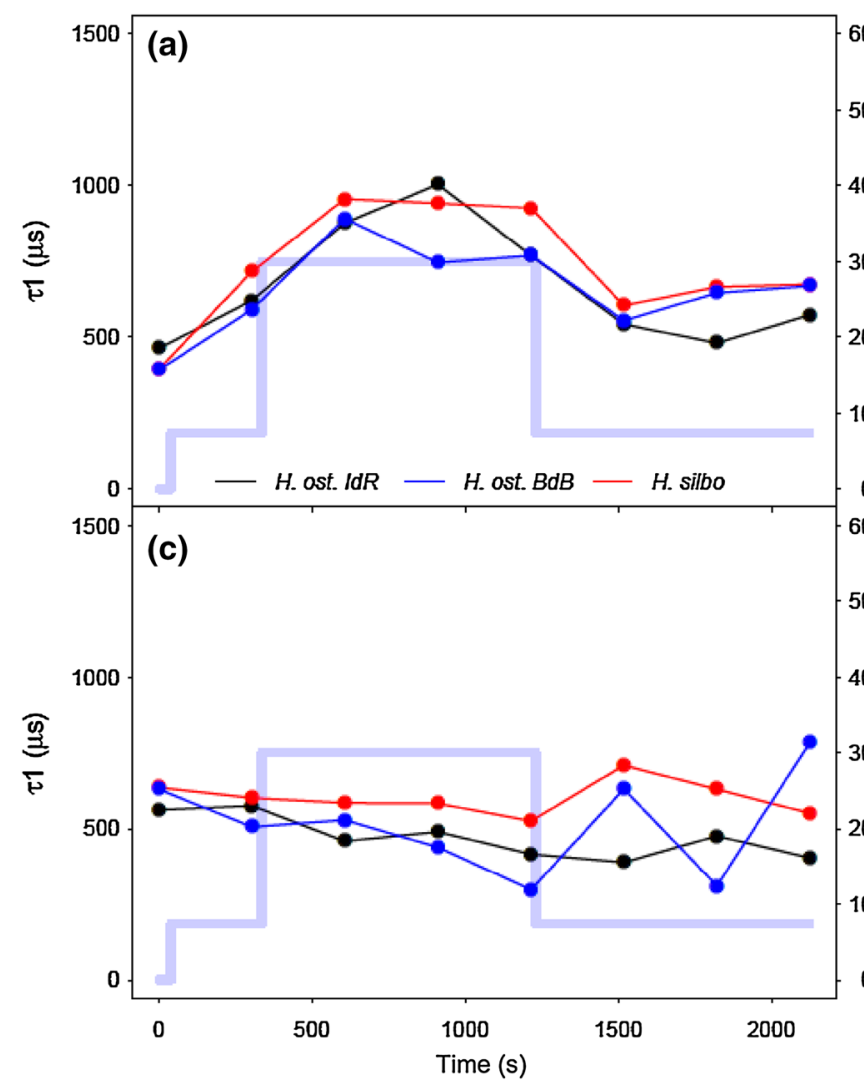

Fig. $8 \tau_{1}$ reaction centre opening $\left(\mathrm{Q}_{\mathrm{A}}-\right.$ oxidation) lifetimes for $H$. ostrearia strain Île de Ré (H. ost. IdR), H. ostrearia strain Baie de Bourgneuf ( $H$. ost. BdB), and $H$. silbo, measured during low light (left column) and high light (right column) induction and recovery curves $(\mathbf{a}, \mathbf{b})$ in the presence of actinic light at the end of each $30 \mathrm{~s}$

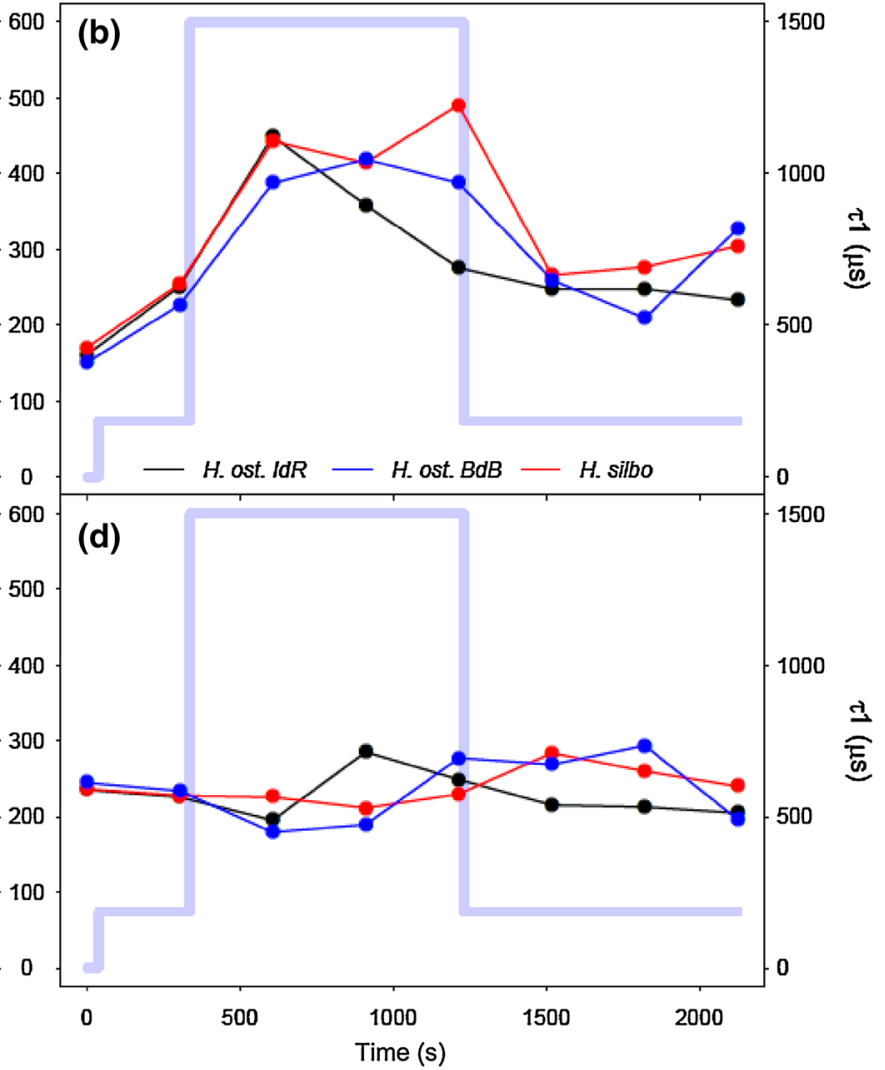

light step, and (c, d) following $1 \mathrm{~s}$ darkness immediately after exposure to each preceding light step. Background trace (light blue line) shows the respective light levels (central axes, PAR $\mu$ mol photons $\mathrm{m}^{-2} \mathrm{~s}^{-1}$ ) applied at each light step 
two-stage process of xanthophyll conversion, de-epoxidation of diadinoxanthin to diatoxanthin, followed by disassociation of fucoxanthin-chlorophyll protein complexes (FCPs) from PSII to act as isolated energy quenchers. This two-stage NPQ model indicates different time scales for induction and relaxation of NPQ that would be unable to respond quickly to the changes in PAR, hence once NPQ was induced, it would not relax with short decreases in light intensity. This would explain the persistence of Y(NPQ) despite reduction in light observed in this study. Such a process seems sensible for cells exposed to repeated rapid changes in light intensity, e.g. within the pelagic and benthic zones of an estuary, where light intensity may rapidly increase and decrease. Lavaud and Goss (2014) also report the ability of diatoms to retain active diatoxanthin in the dark, in readiness for exposure to light and hence a retained capacity for instant downregulation (e.g. Perkins et al. 2002; Serôdio et al. 2005b).

Regulated excitation dissipation in the form of Y(NPQ) was probably the dominant cause of a decrease in PSII cross section, $\sigma_{\mathrm{PSII}}{ }^{\prime}$, observed for Haslea diatoms in this study. $\sigma_{\text {PSII }}$ measures the outcome of two processes, the capture of light by the light-harvesting complex associated with PSII, and the subsequent quantum yield of photochemistry for open PSII reaction centres (Kolber et al. 1998; Suggett et al. 2009). In a study of two prokaryote and two eukaryote taxa of microbial phototrophs, Xu et al. (2017) reported no relationship between $\sigma_{\mathrm{PSII}}$ ' and $\mathrm{Y}(\mathrm{NPQ})$ for the prokaryotes at light levels above the light saturation coefficient, Es. However for the eukaryotes, they reported a progressive decline in $\sigma_{\mathrm{PSII}}{ }^{\prime}$ as $\mathrm{Y}(\mathrm{NPQ})$ increased, although the decrease in normalised $\sigma_{\mathrm{PSII}}{ }^{\prime}$ was proportionally smaller than the increase in Y(NPQ). Xu et al. (2017) further investigated the possibility that this relationship was affected by reaction centre connectivity, i.e. does an increase in $\rho$ counteract the decrease in $\sigma_{\mathrm{PSII}}$ ' induced by $\mathrm{Y}(\mathrm{NPQ})$, but reported no influence on $\sigma_{\mathrm{PSII}}$ ' by $\rho$. This agrees with our findings whereby the increase in Y(NPQ) produced a significant decrease in $\sigma_{\text {PSII }}$ and a concomitant decrease in $\rho$, as excitation pressure (1-qP) increased. Our data demonstrated the presence of an initial decrease in $\sigma_{\mathrm{PSII}}$ due to reaction centre closure, followed by a greater rate of decrease in $\sigma_{\mathrm{PSII}}$ once $\mathrm{Y}(\mathrm{NPQ})$ is induced above a light threshold and, presumably, a threshold of excitation pressure. This has important impacts on the calculation of ETR utilising $\sigma_{\mathrm{PSII}}$ ' without taking into account changes in the latter as light intensity increases. Goss and Lepetit (2015) reported the high capacity of diatoms for NPQ induction and we would therefore expect diatoms, per se, to exhibit a large decrease in $\sigma_{\mathrm{PSII}}{ }^{\prime}$ as light intensity increases, as observed in the present study.

In summary, Haslea diatoms are capable of rapid photoacclimation that alters the relation between ETR and light intensity (PAR), such that ETR is upregulated depending on immediate light history. Furthermore, this increase in ETR occurs despite a concomitant drop in $\sigma_{\mathrm{PSII}}{ }^{\prime}$ caused by induction of energy-dependent excitation dissipation $\mathrm{Y}(\mathrm{NPQ})$. Declines in $\sigma_{\mathrm{PSII}}{ }^{\prime}$ are not compensated for by changes in reaction centre connectivity $(\rho)$, as the latter also decreases with increasing light intensity. The induction of regulated excitation dissipation (Y[NPQ]) after a threshold of light exposure is reached, results in inhibition of non-regulated quenching ( $\mathrm{Y}[\mathrm{NO}])$. These findings have important consequences for our interpretation of photophysiological parameters, and demonstrate the selective advantage of these diatoms in fluctuating light environments through induction of regulated forms of both photochemical and non-photochemical energy dissipation.

Acknowledgements This publication benefited from funding from the European Commission under the Community's Seventh Framework Programme BIOVADIA (Contract No. FP7-PEOPLE2010-IRSES-269294, Biodiversity and Valorisation of Blue Diatoms), and from the Horizon 2020 Research and Innovation Programme GHaNA (The Genus Haslea, New marine resources for blue biotechnology and Aquaculture) under Grant Agreement No 734708/GHANA/ H2020-MSCA-RISE-2016. Equipment used in the study was funded by the New Brunswick Innovation Foundation, the Canada Foundation for Innovation, and the Natural Sciences and Engineering Research Council of Canada.

Open Access This article is distributed under the terms of the Creative Commons Attribution 4.0 International License (http://creativeco mmons.org/licenses/by/4.0/), which permits unrestricted use, distribution, and reproduction in any medium, provided you give appropriate credit to the original author(s) and the source, provide a link to the Creative Commons license, and indicate if changes were made.

\section{References}

Bilger W, Björkman O (1990) Role of the xanthophyll cycle in photoprotection elucidated by measurements of light-induced absorbance changes, fluorescence and photosynthesis in leaves of Hedera canariensis. Photosynth Res 25:173-185. https://doi.org/10.1007/ BF00033159

Cao J, Govindjee (1990) Chlorophyll a fluorescence transient as an indicator of active and inactive photosystem II in thylakoid membranes. Biochim Biophys Acta BBA-Bioenerg 1015:180-188. https://doi.org/10.1016/0005-2728(90)90018-Y

Carvalho AP, Silva SO, Baptista JM, Malcata FX (2011) Light requirements in microalgal photobioreactors: an overview of biophotonic aspects. Appl Microbiol Biotechnol 89:1275-1288. https://doi. org/10.1007/s00253-010-3047-8

Curien G, Flori S, Villanova V et al (2016) The water to water cycles in microalgae. Plant Cell Physiol 57:1354-1363. https://doi. org $/ 10.1093 / \mathrm{pcp} / \mathrm{pcw} 048$

Demmig-Adama B, Adams WW (2006) Photoprotection in an ecological context: the remarkable complexity of thermal energy dissipation. New Phytol 172(1):11-21

Eriksen NT (2008) The technology of microalgal culturing. Biotechnol Lett 30:1525-1536. https://doi.org/10.1007/s 10529-008-9740-3

Gastineau R, Davidovich N, Hansen G, Rines J, Wulff A, Kaczmarska I, Ehrman J, Hermann D, Maumus F, Hardivillier Y, Leignel V, Jacquette B, Méléder V, Hallegraeff G, Yallop M, Perkins RG, 
Cadoret J-P, Saint-Jean B, Carrier G, Mouget J-L (2014) Haslea ostrearia-like diatoms: biodiversity out of the blue. Adv Bot Res 71, 441-465. https://doi.org/10.1016/B978-0-12-408062-1\$40001 $5-9$

Gerotto C, Alboresi A, Meneghesso A et al (2016) Flavodiiron proteins act as safety valve for electrons in Physcomitrella patens. PNAS 113:12322-12327. https://doi.org/10.1073/pnas.1606685113

Goss R, Lepetit B (2015) Biodiversity of NPQ. J Plant Physiol 172:13-32. https://doi.org/10.1016/j.jplph.2014.03.004

Guillard RRL, Ryther JH (1962) Studies of marine planktonic diatoms: I. Cyclotella Nana Hustedt, and Detonula Confervacea (cleve) Gran. Can J Microbiol 8:229-239. https://doi. org/10.1139/m62-029

Ihnken S, Eggert A, Beardall J (2010) Exposure times in rapid light curves affect photosynthetic parameters in algae. Aquat Bot 93:185-194

Ilík P, Pavlovič A, Kouřil R et al (2017) Alternative electron transport mediated by flavodiiron proteins is operational in organisms from cyanobacteria up to gymnosperms. New Phytol 214:967-972. https://doi.org/10.1111/nph.14536

Klughammer C, Schreiber U (2008) Complementary PS II quantum yields calculated from simple fluorescence parameters measured by PAM fluorometry and the Saturation Pulse method. PAM Appl Notes 1:27-35

Kolber ZS, Prášil O, Falkowski PG (1998) Measurements of variable chlorophyll fluorescence using fast repetition rate techniques: defining methodology and experimental protocols. Biochim Biophys Acta BBA-Bioenerg 1367:88-106. https://doi. org/10.1016/S0005-2728(98)00135-2

Kramer DM, Johnson G, Kiirats O, Edwards GE (2004) New fluorescence parameters for the determination of $\mathrm{Q}_{\mathrm{A}}$ redox state and excitation energy fluxes. Photosynth Res 79:209-218. https:// doi.org/10.1023/B:PRES.0000015391.99477.0d

Laney SR (2003) Assessing the error in photosynthetic properties determined with fast repetition rate fluorometry. Limnol Oceanogr 48:2234-2242

Laney SR, Letelier RM (2008) Artifacts in measurements of chlorophyll fluorescence transients, with specific application to fast repetition rate fluorometry. Limnol Oceanogr Methods 6:40-50. https://doi.org/10.4319/lom.2008.6.40

Lavaud J, Goss R (2014) The peculiar features of non-photochemical fluorescence quenching in diatoms and brown algae. In: Demmig-Adams B, Garab G III, Govindjee WA (eds) Non-photochemical quenching and energy dissipation in plants, algae and cyanobacteria. Springer, Netherlands, pp 421-443

Lavaud J, Rousseau B, van Gorkom H, Etienne AL (2002) Influence of the diadinoxanthin pool size on photoprotection in the marine planktonic diatom Phaeodactylum tricornutum. Plant Physiol 129:1398-1406

Lavaud J, Lepetit B (2013) An explanation for the inter-species variability of the photoprotective non-photochemical chlorophyll fluorescence quenching in diatoms. Biochimica et Biophysica Acta (BBA) - Bioenergetics 1827(3):294-302

Lavaud J, Strzepek RF, Kroth PG (2007) Photoprotection capacity differs among diatoms: Possible consequences on the spatial distribution of diatoms related to fluctuations in the underwater light climate. Limnol Oceanogr 52:1188-1194

Lavaud J, Six C, Campbell DA (2016) Photosystem II repair in marine diatoms with contrasting photophysiologies. Photosynth Res 127:189-199. https://doi.org/10.1007/s11120-015-0172-3

Lefebvre S, Mouget J-L, Lavaud J (2011) Duration of rapid light curves for determining the photosynthetic activity of microphytobenthos biofilm in situ. Aquat Bot 95(1):1-8

Lepetit B, Goss R, Jakob T, Wilhelm C (2012) Molecular dynamics of the diatom thylakoid membrane underdifferent light conditions. Photosynth Res 111:245-257
MacIntyre HL, Kana TM, Anning T, Geider R (2002) Photoacclimation of photosynthesis irradiance response curves and photosynthetic pigments in microalgae and cyanobacteria. J Phycol 38(1):17-38

Malviya S, Scalco E, Audic S et al (2016) Insights into global diatom distribution and diversity in the world's ocean. Proc Natl Acad Sci USA 113(11):E1516-E1525. https://doi.org/10.1073/ pnas. 1509523113

McCauley S, Melis A (1987) Quantitation of photosystem II activity in spinach chloroplasts. Effect of artificial quinone acceptors. Photochem Photobiol 46:543-550. https://doi. org/10.1111/j.1751-1097.1987.tb04809.x

Mouget JL, Tremblin G (2002) Suitability of the fluorescence monitoring system (FMS, Hansatech) for measurement of photosynthetic characteristics in algae. Aquat Bot 74(3):219-231

Mouget J-L, Rosa P, Tremblin G (2004) Acclimation of Haslea ostrearia to light of different spectral qualities-confirmation of "chromatic adaptation" in diatoms. J Photochem Photobiol B: Biol 75:1-11

Mouget J-L, Rosa P, Vachoux C, Tremblin G (2005) Enhancement of marennine production by blue light in the diatom Haslea ostrearia. J Appl Phycol 17(5):437-445

Murphy CD, Ni G, Suggett DJ et al (2016) Quantitating active photosystem II reaction center content from fluorescence induction transients. Limnol Ocenogr: Methods 15:54-69

Ni G, Zimbalatti G, Murphy CD, Barnett AB, Arsenault CM, Li G, Cockshutt AM, Campbell DA (2016) Arctic Micromonas uses protein pools and non-photochemical quenching to cope with temperature restrictions on photosystem II protein turnover. Photosynth Res. https://doi.org/10.1007/s11120-016-0310-6

Oxborough K, Baker NR (1997) Resolving chlorophyll a fluorescence images of photosynthetic efficiency into photochemical and non-photochemical components-calculation of $\mathrm{qP}$ and $\mathrm{Fv}^{\prime} /$ Fm'; without measuring Fo'. Photosynth Res 54:135-142. https ://doi.org/10.1023/A:1005936823310

Perkins RG, Mouget J-L, Lefebvre S, Lavaud J (2006) Light response curve methodology and possible implications in the application of chlorophyll fluorescence to benthic diatoms. Mar Biol 149(4):703-712. https://doi.org/10.1007/s00227-005-0222-z

Perkins RG, Oxborough K, Hanlon ARM, Underwood GJC, Baker NR (2002) Can chlorophyll fluorescence be used to estimate the rate of photosynthetic electron transport within microphytobenthic biofilms? Mar Ecol Prog Ser 228:47-56

Perkins RG et al (2010) The application of variable chlorophyll fluorescence to microphytobenthic biofilms. In: Suggett D, Prášil O, Borowitzka M (eds) Chlorophyll a fluorescence in aquatic sciences: methods and applications. Developments in applied phycology, vol 4. Springer, Dordrecht

Perkins RG, Bagshaw E, Mol L, Williamson CJ, Fagan D, Gamble M, Yallop M (2017) Photoacclimation by Arctic cryoconite phototrophs. FEMS Microbiol Ecol 93(5):1-10

R Core Team (2013) R: a language and environment for statistical computing. R Foundation for Statistical Computing, Vienna, Austria

Ralph PJ, Gademann R (2005) Rapid light curves: a powerful tool to assess photosynthetic activity. Aquat Bot 82(3):222-237

Ruban A, Lavaud J, Rousseau B et al (2004) The super-excess energy dissipation in diatom algae: comparative analysis with higher plants. Photosynth Res 82:165. https://doi.org/10.1007/s1112 0-004-1456-1

Serôdio J, Cruz S, Vieira S, Brotas V (2005a) Non-photochemical quenching of chlorophyll fluorescence and operation of the xanthophyll cycle in estuarine microphytobenthos. J Exp Mar Biol Ecol 326:157-169. https://doi.org/10.1016/j.jembe.2005.05.011

Serôdio J, Vieira S, Cruz S, Barroso F (2005b) Short-term variability in the photosynthetic activity of microphytobenthos as detected 
by measuring rapid light curves using variable fluorescence. Mar Biol 146(5):903-914

Sforza E, Simionato D, Giacometti GM, Bertucco A, Morosinotto T (2012) Adjusted light and dark cycles can optimize photosynthetic efficiency in algae growing in photobioreactors. PLoS ONE 7(6):e38975. https://doi.org/10.1371/journal.pone.0038975

Suggett D, MacIntyre H, Kana T, Geider R (2009) Comparing electron transport with gas exchange: parameterising exchange rates between alternative photosynthetic currencies for eukaryotic phytoplankton. Aquat Microb Ecol 56:147-162. https://doi. org/10.3354/ame01303

Ting CS, Owens TG (1993) Photochemical and non-photochemical fluorescence quenching processes in the diatom Phaeodactylum tricornutum. Plant Physiol 101:1323-1330

Underwood GJC, Kromkamp J (1999) Primary production by phytoplankton and microphytobenthos in estuaries. Adv Ecol Res 29:93-153 van Kooten O, Snel JF (1990) The use of chlorophyll fluorescence nomenclature in plant stress physiology. Photosynth Res 25:147150. https://doi.org/10.1007/BF00033156

Vanormelingen P, Verleyen E, Vyverman W (2008) The diversity and distribution of diatoms: from cosmopolitanism to narrow endemism. Biodivers Conserv 7:393-405. https://doi.org/10.1007/ s10531-007-9257-4

White AJ, Critchley C (1999) Rapid light curves: a new fluorescence method to assess the state of the photosynthetic apparatus. Photosynth Res 59:63-72

Xu K, Grant-Burt JL, Donaher N, Campbell DA (2017) Connectivity among photosystem II centers in phytoplankters: patterns and responses. Biochim Biophys Acta BBA-Bioenerg. https://doi. org/10.1016/j.bbabio.2017.03.003

Yallop M, Anesio A, Perkins RG et al (2012) Photophysiology and albedo-changing potential of the ice algal community on the surface of the Greenland ice sheet. ISME J 6:2302-2313 